\title{
Effects of angiotensin II type 1 receptor blocker on ambulatory blood pressure variability in hypertensive patients with overt diabetic nephropathy
}

\author{
Shin-ichiro Masuda, Kouichi Tamura, Hiromichi Wakui, Tomohiko Kanaoka, Masato Ohsawa, Akinobu Maeda,
} Toru Dejima, Mai Yanagi, Koichi Azuma and Satoshi Umemura

Previous studies have shown increases in ambulatory short-term blood pressure (BP) variability to be related to cardiovascular disease. In this study, we examined whether the angiotensin II type 1 receptor blocker (ARB) would improve ambulatory shortterm BP variability in hypertensive patients with diabetic nephropathy. A total of $\mathbf{3 0}$ patients with type II diabetes, along with hypertension and overt nephropathy, were enrolled in this randomized, two-period, crossover trial of 12 weeks of treatment with losartan $(50 \mathrm{mg}$ daily) and telmisartan $(\mathbf{4 0} \mathrm{mg}$ daily). At baseline and at the end of each treatment period, 24-h ambulatory BP monitoring with power spectral analysis of heart rate and measurements of proteinuria, estimated glomerular filtration rate and brachial-ankle pulse wave velocity (baPWV) were performed. After 12 weeks of treatment, 24-h, daytime and nighttime shortterm BP variability, assessed on the basis of the coefficient of variation of ambulatory BP, was significantly decreased by telmisartan. Both losartan and telmisartan reduced urinary protein excretion and baPWV. However, compared with losartan, telmisartan significantly decreased urinary protein excretion, baPWV and low-frequency (LF)-to-high-frequency (HF) ratio, an index of sympathovagal balance. Multiple regression analysis showed significant correlations between urinary protein excretion and baPWV, 24-h LF-to-HF ratio, nighttime systolic BP and 24-h short-term systolic BP variability. These results suggest that ARB, particularly telmisartan, is effective in reducing proteinuria in hypertensive patients with overt diabetic nephropathy, partly through inhibitory effects on ambulatory short-term BP variability and sympathetic nerve activity, in addition to its longer duration of action on nighttime BP reduction.

Hypertension Research (2009) 32, 950-955; doi:10.1038/hr.2009.131; published online 28 August 2009

Keywords: ambulatory blood pressure monitoring; diabetes mellitus; proteinuria; pulse wave velocity; renin-angiotensin system

\section{INTRODUCTION}

Cardiovascular disease is the main cause of death in diabetic patients with nephropathy, ${ }^{1}$ and hypertension is a major risk factor for cardiovascular disease in these patients. ${ }^{2}$ In particular, findings of pathological cardiovascular remodeling such as atherosclerosis are frequently found in diabetic patients with nephropathy, and have been identified as independent risk factors for mortality. ${ }^{3,4}$ Cardiovascular remodeling is an adaptive response to hemodynamic as well as nonhemodynamic stimuli, such as hypertension and vasoactive agents. Therefore, the intensive management of hypertension is critically important for the prevention of cardiovascular complications in patients with diabetic nephropathy.

Ambulatory blood pressure (BP) monitoring allows the acquisition of critical information on not only the average 24-h BP but also on the variations in $\mathrm{BP}$ values that occur in the course of daily life. Among the several parameters obtained by ambulatory $\mathrm{BP}$ monitoring, previous studies have shown that $\mathrm{BP}$ variability is a complex pheno- menon that involves both short- and long-lasting changes. ${ }^{5}$ Thus, the 24-h BP varies not only because of a reduction in BP during nighttime sleep and an increase in the morning, but also because of sudden, quick and short-lasting changes that occur both during the day and, to a lesser extent, at night. This phenomenon, short-term BP variability, has been shown to depend on sympathetic vascular modulation and on atherosclerotic vascular changes. ${ }^{5,6}$ Short-term BP variability is suggested to be clinically relevant by the fact that hypertensive patients with similar 24-h mean BP values exhibit more severe organ damage when the short-term BP variability is greater. ${ }^{5,7}$ In addition, we, along with others, have reported that short-term BP variability, estimated as the s.d. or coefficient of variation in noninvasive ambulatory BP monitoring, is associated with cardiovascular disease. ${ }^{7-12}$

The circadian pattern of BP in diabetic patients has been found to exhibit a blunted nocturnal decrease in $\mathrm{BP}$, which is associated with autonomic neuropathy and nephropathy. ${ }^{13,14}$ The loss of nocturnal BP dipping has been considered to be a risk factor for the progression of 
nephropathy and to be of prognostic value with respect to target organ damage and cardiovascular morbidity in both diabetic and hypertensive patients. ${ }^{15-20}$ With respect to the pathological significance of short-term BP variability in diabetics, a recent study showed nighttime short-term BP variability to be related to cardiovascular events in type II diabetic patients, ${ }^{21}$ and thus short-term BP variability may take part in the progression of diabetic nephropathy and associated cardiovascular complications. Therefore, more and better evidence on shortterm BP variability could lead to a more precise understanding of the pathogenesis, and hence potential treatment, of diabetic nephropathy and its cardiovascular complications.

Activation of the renin-angiotensin system is also shown in the pathogenesis of diabetic nephropathy and its cardiovascular complications through the generation of angiotensin II (Ang II), a key regulator of cardiovascular homeostasis. The Ang II type 1 receptor (AT1 receptor) is responsible for most of the pathophysiological actions of Ang II, and AT1 receptor blockers (ARBs) have been shown to exert various protective effects on diabetic nephropathy and its cardiovascular complications, at least partially, through a reduction in urinary protein excretion. ${ }^{22}$ However, there have been no studies examining the effects of ARB on short-term BP variability and comparing the associations of BP variability with urinary protein excretion and atherosclerosis in hypertensive patients with type II diabetes. Furthermore, previous studies have reported that telmisartan has a long-term half-life with peroxisome proliferator-activated receptor- $\gamma$-activating property and a recent AMADEO study showed that telmisartan is superior to losartan in reducing proteinuria in hypertensive patients with diabetic nephropathy. ${ }^{23,24}$ Therefore, in this study, we examined the possible effects of ARB losartan and telmisartan on diurnal BP profile, including the ambulatory short-term BP variability in hypertensive type II diabetic patients with overt nephropathy.

\section{METHODS}

\section{Study design and population}

This study was a prospective, randomized and crossover trial consisting of a 4-week observation period and two treatment periods, each lasting 12 weeks. After the observation period, along with the discontinuation of any previous $A R B$, eligible patients were randomized to either losartan or telmisartan treatment with a crossover to another ARB. The once-daily dose was $50 \mathrm{mg}$ for losartan and $40 \mathrm{mg}$ for telmisartan, and patients were asked to take the ARB once in the morning everyday. Other medications were not changed during the whole study period, including the observation period.

Inclusion criteria were an age $\geqslant 18$ years, a history of type II diabetes mellitus, mild-to-moderate hypertension (clinic systolic $\mathrm{BP} \geqslant 130 \mathrm{~mm} \mathrm{Hg}$ and/ or diastolic $\mathrm{BP} \geqslant 80 \mathrm{~mm} \mathrm{Hg}$ or receiving antihypertensives), urinary protein excretion $\geqslant 0.3 \mathrm{~g}$ per day and serum creatinine $<3 \mathrm{mg}$ per $100 \mathrm{ml}$. Urinalysis was performed to eliminate the possibility of other abnormalities, such as hematuria and so on. Exclusion criteria included patients who were receiving an angiotensin-converting enzyme inhibitor, women who were nursing or pregnant, patients with nondiabetic renal disease, clinically significant heart disease, stroke, renal artery stenosis, hepatic dysfunction and known hypersensitivity to any component of the study medications.

Proteinuria was determined as the geometric mean of three consecutive 24-h urine collections, completed immediately before the visit at the end of the observation period and each treatment period. Venous blood samples for measurement of hematological and biochemical parameters were collected in the morning after an overnight fast on the same day. Renal function was assessed with the estimated glomerular filtration rate using the abbreviated MDRD (Modification of Diet in Renal Disease) Study equation modified by a Japanese coefficient. ${ }^{25}$ The study was approved by the ethics committee of Yokohama City University Hospital, and written informed consent was obtained from every subject.

\section{Determination of 24-h BP and short-term BP variability}

Ambulatory BP monitoring was performed at the end of the observation period and each treatment period. Ambulatory BP and heart rates (HRs) were monitored every $30 \mathrm{~min}$ using a fully automated device (TM-2425, A\&D, Tokyo, Japan), essentially as described previously. ${ }^{26}$ The patients were instructed to fill out a diary to record the time of sleeping, rising and other daytime activities. Therefore, the term 'day' and 'night' hours used in this study reflect the average period during which the subjects were awake/upright and asleep/supine, respectively.

Short-term BP variability, which comprised coefficients of variation of BP values obtained from ambulatory BP monitoring, is defined as the withinsubject s.d. of all systolic and diastolic readings at 30-min intervals divided by mean BP during the course of the measurement periods. HR variability, which comprised the coefficients of variation of HR values, is defined as the withinsubject s.d. of all HR values at 30-min intervals divided by mean HR. ${ }^{8,9,26}$

\section{Electrocardiogram and power spectral analysis of $\mathbf{R}-\mathbf{R}$ intervals}

Electrocardiogram tracings were obtained with a precordial lead (V5) with ambulatory BP monitoring, and variations in R-R intervals and ST level trendgrams were analyzed as described previously. ${ }^{27}$ Briefly, $512 \mathrm{R}-\mathrm{R}$ intervals were recorded at a resolution of $7.8 \mathrm{~ms}$ and were analyzed after fast Fourier transformation using appropriate software (A\&D). The power spectral densities of oscillations were divided into two ranges: a low-frequency (LF) component in the range of $0.05-0.15 \mathrm{~Hz}$ and a high-frequency (HF) component in the range of $0.15-0.4 \mathrm{~Hz}$, as an index of parasympathetic nerve activity. The LF-toHF ratio was calculated as an index of sympathovagal balance.

\section{Brachial-ankle pulse wave velocity}

The brachial-ankle pulse wave velocity (baPWV) values were determined using a PP analyzer (model: BP-203RPEII; Nihon Colin, Tokyo, Japan). Pulse volume waveforms were recorded with sensors placed over the right brachial artery and both tibial arteries. The baPWV values measured using this method are reported to significantly correlate with the aortic PWV measured by the catheter method ${ }^{28}$

\section{Statistical analysis}

Quantitative data are expressed as means \pm s.e.m. For the statistical analysis of difference between groups, analysis of variance, followed by Scheffe's F-test, was used. Paired samples were compared by a paired comparison's $t$-test. A $P$-value $<0.05$ was considered to be statistically significant.

\section{RESULTS}

The main characteristics of the study patients at baseline are shown in Table 1. Although the values of body mass index $\left(29.3 \pm 1.6 \mathrm{~kg} \mathrm{~m}^{-2}\right)$ were apparently greater than normal range values $\left(18.5-24.9 \mathrm{~kg} \mathrm{~m}^{-2}\right)$, we did not evaluate the patients for possible complications of sleep apnea syndrome.

\section{Effects of losartan and telmisartan on ambulatory BP and its short- term variability}

Table 2 shows 24-h, daytime and nighttime ambulatory BP and HR values, and their variability at baseline and after 12 weeks of treatment with losartan or telmisartan. Both losartan and telmisartan significantly decreased all the values of 24-h, daytime and nighttime ambulatory BP after the 12-week treatment. Although telmisartan treatment significantly decreased 24 -h, daytime and nighttime HR, losartan treatment lowered only nighttime HR. With respect to shortterm BP variability, telmisartan significantly decreased the values of $24-\mathrm{h}$, daytime and nighttime systolic/diastolic BP variability. However, losartan did not affect the values of short-term BP variability. Overall, telmisartan treatment caused a significantly greater improvement in nighttime systolic BP and 24-h, daytime and nighttime systolic/ diastolic BP variability, with a decrease in 24-h and daytime HR and an increase in nighttime HR variability. 
Effects of losartan and telmisartan on the power spectral analysis of $\mathbf{R}-\mathbf{R}$ intervals

Table 3 shows 24-h, daytime and nighttime LF-to-HF ratios at baseline and after 12 weeks of treatment with losartan or telmisartan. Although both losartan and telmisartan treatments significantly decreased 24-h

Table 1 Demographic characteristics at baseline

\begin{tabular}{|c|c|}
\hline Gender (male/female) & $18 / 12$ \\
\hline Age (year) & $61.2 \pm 2.5$ \\
\hline Body mass index $\left(\mathrm{kg} \mathrm{m}^{-2}\right)$ & $29.3 \pm 1.6$ \\
\hline \multicolumn{2}{|l|}{ Antihypertensive medication } \\
\hline Calcium channel blockers & 18 \\
\hline Thiazide diuretics & 7 \\
\hline$\alpha$-Blockers & 5 \\
\hline \multicolumn{2}{|l|}{ Hypoglycemic medication } \\
\hline Glibenclamide & 12 \\
\hline Voglibose & 7 \\
\hline Nateglinide & 5 \\
\hline Glimepiride & 2 \\
\hline Gliclazide & 2 \\
\hline $\mathrm{HbA} 1 \mathrm{c}(\mathrm{mg}$ per $100 \mathrm{ml})$ & $7.2 \pm 0.2$ \\
\hline Serum creatinine (mg per $100 \mathrm{ml}$ ) & $1.15 \pm 0.09$ \\
\hline Estimated GFR ( $\mathrm{ml} \mathrm{min}-1$ per $\left.1.73 \mathrm{~m}^{2}\right)$ & $51.1 \pm 4.9$ \\
\hline Urinary protein excretion (g per day) & $3.3 \pm 0.2$ \\
\hline
\end{tabular}

Abbreviations: GFR, glomerular filtration rate; $\mathrm{HbAlc}$, hemoglobin Alc.

Values are means \pm s.e.m. and nighttime LF-to-HF ratios, only telmisartan treatment significantly lowered the daytime LF-to-HF ratio. As a result, telmisartan treatment caused a significantly greater improvement in 24-h and daytime LF-to-HF ratios.

\section{Effects of losartan and telmisartan on urinary protein excretion} and baPWV

Although the 12-week losartan and telmisartan treatments did not affect the estimated glomerular filtration rate, these treatments significantly decreased urinary protein excretion, and telmisartan treatment did result in a greater improvement in the urinary protein excretion (Figure 1). Furthermore, although baPWV was decreased by both losartan and telmisartan treatments, telmisartan brought about a greater improvement in baPWV (Figure 1). With respect to glycemic control, the values of HbAlc (hemoglobin Alc) did not differ significantly after the 12-week losartan and telmisartan treatments (data not shown).

\section{Multiple regression analysis for the determination of factors contributing to the regression of proteinuria}

The results of ambulatory BP profiling in Table 2, power spectral analysis in Table 3 and measurement of baPWV and urinary protein excretion in Figure 1 showed that telmisartan treatment improved 24-h, daytime and nighttime systolic/diastolic BP variability, 24-h and daytime HR, nighttime systolic BP, nighttime HR variability, 24-h and daytime LF-to-HF ratios, as well as baPWV, with a concomitant reduction in proteinuria, better than losartan treatment. Therefore, we chose these parameters for a further regression analysis to examine factors important for the regression of proteinuria. Multivariate

Table 2 Ambulatory BP and its variability before and after AT1 receptor blocker therapy

\begin{tabular}{|c|c|c|c|c|c|c|}
\hline & Baseline & Losartan & Telmisartan & P-value & $\mathrm{P}$-value ${ }^{\mathrm{a}}$ & $\mathrm{P}$-value $\mathrm{b}^{\mathrm{b}}$ \\
\hline \multicolumn{7}{|l|}{$24-h$} \\
\hline Systolic BP (mm Hg) & $148 \pm 2$ & $131 \pm 1$ & $128 \pm 3$ & $<0.001$ & $<0.001$ & 0.2 \\
\hline Diastolic BP (mm Hg) & $81 \pm 1$ & $74 \pm 1$ & $75 \pm 1$ & $<0.001$ & $<0.001$ & 0.3 \\
\hline HR (b.p.m.) & $76 \pm 2$ & $75 \pm 2$ & $72 \pm 2$ & 0.2 & 0.007 & 0.01 \\
\hline Systolic BP variability (\%) & $14.1 \pm 0.6$ & $14.5 \pm 0.5$ & $12.4 \pm 0.3$ & 0.7 & 0.01 & $<0.001$ \\
\hline Diastolic BP variability (\%) & $15.6 \pm 0.7$ & $15.3 \pm 0.5$ & $13.2 \pm 0.3$ & 0.7 & 0.002 & 0.002 \\
\hline HR variability (\%) & $12.4 \pm 0.6$ & $13.8 \pm 0.7$ & $14.7 \pm 0.6$ & 0.2 & 0.01 & 0.2 \\
\hline \multicolumn{7}{|l|}{ Daytime } \\
\hline Systolic BP (mm Hg) & $152 \pm 2$ & $133 \pm 2$ & $132 \pm 2$ & $<0.001$ & $<0.001$ & 0.3 \\
\hline Diastolic BP (mm Hg) & $86 \pm 1$ & $77 \pm 1$ & $76 \pm 2$ & $<0.001$ & $<0.001$ & 0.5 \\
\hline HR (b.p.m.) & $79 \pm 2$ & $79 \pm 2$ & $73 \pm 2$ & 0.9 & 0.02 & 0.003 \\
\hline Systolic BP variability (\%) & $13.3 \pm 0.5$ & $14.1 \pm 0.6$ & $11.8 \pm 0.4$ & 0.3 & 0.009 & $<0.001$ \\
\hline Diastolic BP variability (\%) & $16.7 \pm 0.7$ & $16.2 \pm 0.8$ & $13.3 \pm 0.4$ & 0.7 & 0.001 & 0.006 \\
\hline HR variability $(\%)$ & $12.7 \pm 0.8$ & $13.4 \pm 0.7$ & $14.7 \pm 0.9$ & 0.5 & 0.1 & 0.2 \\
\hline \multicolumn{7}{|l|}{ Nighttime } \\
\hline Systolic BP (mm Hg) & $139 \pm 3$ & $128 \pm 2$ & $123 \pm 2$ & $<0.001$ & $<0.001$ & 0.01 \\
\hline Diastolic BP (mm Hg) & $78 \pm 1$ & $70 \pm 1$ & $70 \pm 2$ & $<0.001$ & $<0.001$ & 0.9 \\
\hline HR (b.p.m.) & $73 \pm 1$ & $70 \pm 2$ & $68 \pm 2$ & 0.04 & 0.007 & 0.06 \\
\hline Systolic BP variability (\%) & $13.6 \pm 0.7$ & $12.1 \pm 0.5$ & $9.7 \pm 0.3$ & 0.1 & $<0.001$ & 0.002 \\
\hline Diastolic BP variability (\%) & $13.1 \pm 0.5$ & $13.5 \pm 0.7$ & $11.4 \pm 0.4$ & 0.7 & 0.007 & 0.03 \\
\hline HR variability $(\%)$ & $7.5 \pm 0.6$ & $7.1 \pm 0.5$ & $9.2 \pm 0.7$ & 0.5 & 0.04 & 0.002 \\
\hline Nocturnal BP fall (mm Hg) & $13.1 \pm 2.7$ & $5.1 \pm 1.9$ & $8.9 \pm 2.4$ & 0.002 & 0.2 & 0.1 \\
\hline
\end{tabular}

Abbreviations: AT1, angiotensin II type 1; BP, blood pressure; b.p.m., beats per minute; HR, heart rate. Values are means \pm s.e.m. $P$-values of losartan treatment vs. baseline.

a $P$-values of telmisartan treatment vs. baseline.

b $P$-values of telmisartan treatment vs. losartan treatment. 
Table 3 Power spectral analysis of R-R intervals before and after AT1 receptor blocker therapy

\begin{tabular}{|c|c|c|c|c|c|c|}
\hline & Baseline & Losartan & Telmisartan & P-value & P-value & P-value \\
\hline LF-to-HF ratio & $1.74 \pm 0.10$ & $1.47 \pm 0.10$ & $1.27 \pm 0.11$ & 0.004 & $<0.001$ & 0.002 \\
\hline \multicolumn{7}{|l|}{ Daytime: } \\
\hline LF-to-HF ratio & $1.74 \pm 0.10$ & $1.58 \pm 0.11$ & $1.29 \pm 0.12$ & 0.1 & 0.002 & $<0.001$ \\
\hline \multicolumn{7}{|l|}{ Nighttime: } \\
\hline
\end{tabular}

Abbreviations: AT1, angiotensin II type 1; BP, blood pressure; HF, high frequency; HR, heart rate; LF, low frequency.

Values are means \pm s.e.m. $P$-values of losartan treatment $v$ s. baseline.

a $P$-values of telmisartan treatment $v s$. baseline.

b $P$-values of telmisartan treatment vs. losartan treatment.
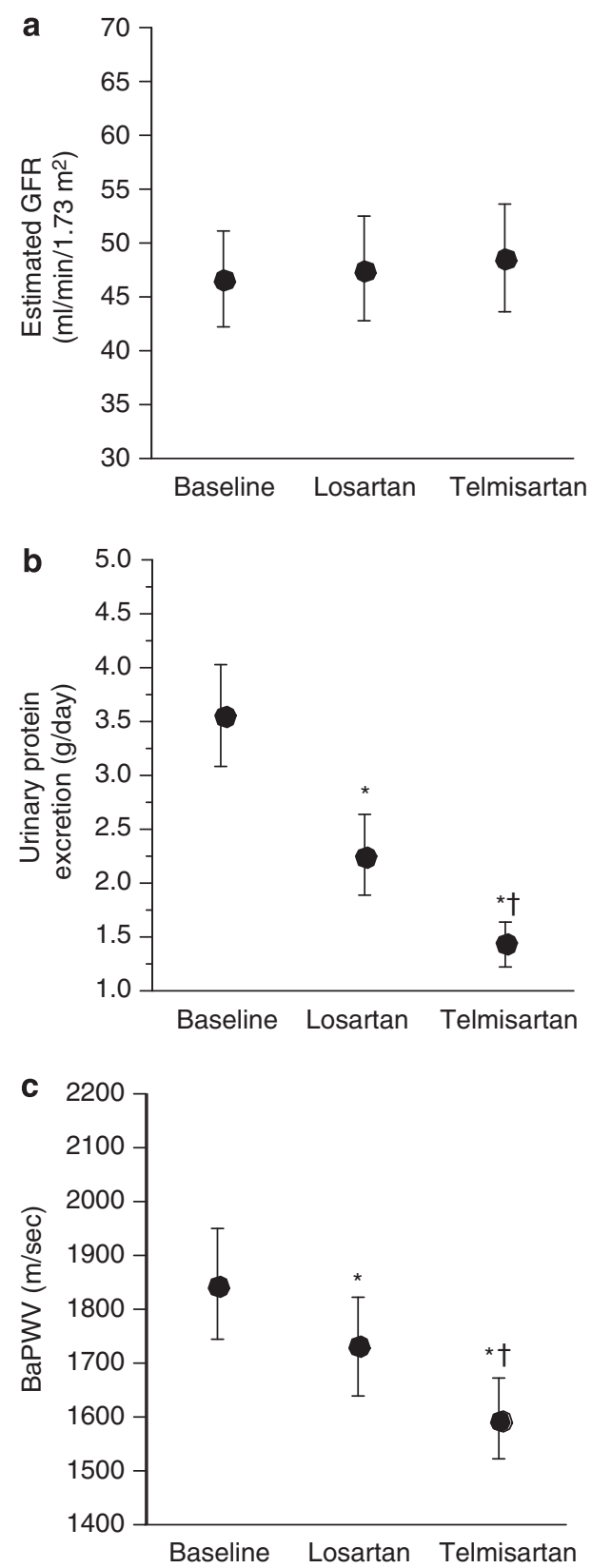

Figure 1 Effects of losartan and telmisartan on the estimated glomerular filtration rate (eGFR) (a), urinary protein excretion (b) and brachial-ankle pulse wave velocity (baPWV) (c). ${ }^{*} P<0.05$ vs. baseline; ${ }^{\dagger} P<0.05$ telmisartan vs. Iosartan. Values are expressed as means \pm s.e.m.
Table 4 Multivariate stepwise linear regression analysis of urinary protein excretion

\begin{tabular}{lcccc}
\hline Variables & Coefficient & $\begin{array}{c}\text { Lower 95\% } \\
\text { interval }\end{array}$ & $\begin{array}{c}\text { Upper 95\% } \\
\text { interval }\end{array}$ & P-value \\
\hline 24-h HR & 0.0582 & 0.0343 & 0.0821 & 0.013 \\
24-h systolic BP variability & 0.1257 & 0.0418 & 0.2095 & 0.008 \\
Nighttime systolic BP & 0.0286 & 0.0126 & 0.0445 & 0.005 \\
24-h LF-to-HF ratio & 0.8959 & 0.5109 & 1.2810 & 0.003 \\
baPWV & 0.0034 & 0.0029 & 0.0039 & 0.002
\end{tabular}

Abbreviations: baPWV, brachial-ankle pulse wave velocity; BP, blood pressure; HF, high frequency; HR, heart rate; LF, low frequency.

The independent variables entered in the model for multivariate stepwise regression analysis are as follows; 24-h, daytime and nighttime systolic BP variability, 24-h and daytime HR, nighttime systolic BP, nighttime HR variability, 24-h and daytime LF-to-HF ratios and baPWV. The variables which showed a $P$-value $\geqslant 0.05$ in the multivariate relations were excluded from the table $\left(R^{2}=0.8134, P<0.001\right)$.

stepwise linear regression analysis of urinary protein excretion for variables including 24-h, daytime and nighttime systolic BP variability, 24-h and daytime HR, nighttime systolic BP, nighttime HR variability, 24-h and daytime LF-to-HF ratios, as well as baPWV indicated significant associations between urinary protein excretion and 24-h HR, 24-h systolic BP variability, 24-h LF-to-HF ratio and nighttime systolic BP (Table 4). Urinary protein excretion was also significantly associated with baPWV (Table 4).

\section{DISCUSSION}

The results of this study show that both losartan (50 mg daily) and telmisartan (40 mg daily) treatments significantly decreased 24-h, daytime, nighttime ambulatory $\mathrm{BP}, \mathrm{baPWV}$ and urinary protein excretion in hypertensive patients with overt type II diabetic nephropathy. However, telmisartan $40 \mathrm{mg}$ decreased nighttime systolic BP and 24-h, daytime and nighttime systolic/diastolic short-term BP variability, baPWV, as well as urinary protein excretion better than losartan $50 \mathrm{mg}$. These data suggest that the benefit of ARB therapy, particularly telmisartan, for patients with hypertension and overt diabetic nephropathy, results from inhibition of proteinuria and pathological vascular remodeling, at least in part, through improvements in the nighttime BP level and 24-h short-term BP variability.

In this study, the coefficient of variation in the BP measured every 30 min was used as an index of short-term BP variability to assess the circadian BP patterns in hypertensive patients with overt diabetic nephropathy. Although the sympathovagal balance is reported to be a major determinant of short-term BP variability, it is also affected by atherosclerotic changes in the vascular wall in patients with cardiovascular disease. ${ }^{5,6}$ The increase in short-term BP variability may be 
partly explained by a disordered baroreflex function associated with autonomic neuropathy and an increased stiffness of large elastic arteries. Several previous studies have reported that short-term BP variability estimated by noninvasive ambulatory $\mathrm{BP}$ monitoring is associated with cardiovascular disease in hypertensive patients. ${ }^{8-10}$ The results of our previous cross-sectional study also showed that short-term BP variability was significantly increased in overt diabetic nephropathy patients with coronary artery disease, ${ }^{26}$ and in particular, an increase in nighttime short-term BP variability was associated with the plasma concentration of noradrenaline, as well as with the prevalence of coronary artery disease in these diabetic nephropathy patients. ${ }^{26}$

There is a well-established role for the renin-angiotensin system in promoting hypertension- and diabetes-related organ damage, including atherosclerosis and diabetic nephropathy. Reducing proteinuria is critically important for the regression of chronic kidney disease including diabetic nephropathy, ${ }^{29}$ and evidence indicates that ARB not only prevents progression but also induces a reversal of diabetic nephropathy, mainly by reducing proteinuria. ${ }^{22}$ The results of this study show that decreases in the mean ambulatory BP levels during both day and night were accompanied by decreases in short-term BP variability by telmisartan. Thus, it is likely that telmisartan is effective for the improvement of short-term BP variability in addition to its general BP-lowering effect in hypertensive patients with overt diabetic nephropathy.

Although a recent AMADEO study showed that telmisartan was more effective than losartan in reducing proteinuria in hypertensive patients with diabetic nephropathy at levels of BP that were not different between the telmisartan and losartan treatment groups, the possible mechanisms involved in this difference in antiproteinuric effect were not elucidated. ${ }^{24}$ In this study, a more beneficial effect of telmisartan in reducing urinary protein excretion than losartan was accompanied by a more potent inhibitory effect of telmisartan on short-term BP variability and by its better lowering effect on nighttime systolic BP. Impaired diurnal autonomic nervous rhythm and proteinuria are closely related to the blunted decline in nocturnal BP and the resultant increase in nighttime $\mathrm{BP}$, which is mainly caused by the comparative increase in sympathetic nerve activity. ${ }^{30,31}$ We previously showed that short-term BP variability was increased, at least partly, by the relative predominance of sympathetic nerve activity. ${ }^{26}$ In this study, the decreasing effects of telmisartan on short-term BP variability and nighttime BP level were accompanied by a reduction in the LF-to-HF ratio, an important index of sympathetic nerve activity. ${ }^{32}$ Numerous studies have shown that Ang II enhances the sympathetic nervous system at various levels through the activation of presynaptically located AT1 receptor, and the sympatholytic properties of ARB have been examined. ${ }^{33,34}$ Previous studies have shown that the order of potency of the sympatho-inhibitory effect was telmisartan $>$ losartan in several different experimental models. ${ }^{35}$

Importantly, accumulated evidence indicated that telmisartan has a longer half-life, and thus a longer duration of action, than does losartan. ${ }^{36}$ For example, a previous comparison of the antihypertensive profiles of telmisartan and losartan on ambulatory BP disclosed that telmisartan $40 \mathrm{mg}$ once daily produced a significantly greater BP reduction, particularly during nighttime, than did losartan $50 \mathrm{mg}$ once daily in patients with mild-to-moderate hypertension, ${ }^{37}$ and other studies reported that the BP-lowering effects of telmisartan were stronger than those of losartan in the morning and during the last $6 \mathrm{~h}$ of the 24 -h dosing interval. ${ }^{38,39}$ Therefore, although we have not directly examined the effects of losartan and telmisartan on morning BP profile, including morning BP surge and on possible relationships between morning BP and urinary protein excretion in this study, the beneficial effect of telmisartan on reducing proteinuria should be, at least partly, because of a longer half-life and more potent action on nighttime BP lowering at a once-daily dose.

As a limitation of this study, the use of a single dose of losartan (50 mg) and telmisartan $(40 \mathrm{mg}$ ) allows no definite conclusions with regard to relative efficacies at this stage in the absence of multiple dose comparisons. For example, if losartan is administered at a twice-daily dose or a larger dose, the results of comparison between losartan and telmisartan with respect to diurnal BP profile and urinary protein excretion may differ from the results of this and it may happen that losartan shows equal or more beneficial effects. Therefore, we need to perform multiple dose comparisons in a future study.

Finally, the multiple regression analysis showed significant correlations between urinary protein excretion and baPWV, 24-h LF-to-HF ratio, nighttime systolic BP, 24-h short-term systolic BP variability and 24-h HR. These results suggest that short-term BP variability, as well as nocturnal BP and sympathetic nervous system activity, can impact the progression of overt diabetic nephropathy by exerting an influence on urinary protein excretion. In addition, there was a significant correlation between urinary protein excretion and baPWV. Recent studies have shown urinary protein excretion to be more closely associated with baPWV than with ambulatory BP level, ${ }^{40}$ and that baPWV increased with a decrease in renal function or with proteinuria independently of other risk factors, ${ }^{41}$ thereby supporting the results of this study.

In conclusion, the results of this study suggest that decreases in nighttime BP and short-term BP variability may be involved in the additional beneficial suppression of proteinuria in hypertensive patients with overt diabetic nephropathy. Furthermore, telmisartan may exert its renal protective effects partly through an inhibitory effect on short-term BP variability and sympathetic nerve activity, in addition to its longer duration of action on nighttime BP reduction.

\section{CONFLICT OF INTEREST}

The authors declare no conflict of interest.

\section{ACKNOWLEDGEMENTS}

This study was supported by Grants from the Japan Society for the Promotion of Science, the Yokohama Foundation for Advancement of Medical Science, Takeda Science Foundation, Salt Science Research Foundation (No. 0911), The Kidney Foundation, Japan (JKFB09-25), and the Strategic Research Project of Yokohama City University. We thank Dr Boru for the English editing of this paper.

1 Adler Al, Stevens RJ, Manley SE, Bilous RW, Cull CA, Holman RR. Development and progression of nephropathy in type 2 diabetes: the United Kingdom Prospective Diabetes Study (UKPDS 64). Kidney Int 2003; 63: 225-232.

2 Adler AI, Stratton IM, Neil HA, Yudkin JS, Matthews DR, Cull CA, Wright AD, Turner RC, Holman RR. Association of systolic blood pressure with macrovascular and microvascular complications of type 2 diabetes (UKPDS 36): prospective observational study. BMJ 2000; 321: 412-419.

3 Stevens RJ, Kothari V, Adler AI, Stratton IM. The UKPDS risk engine: a model for the risk of coronary heart disease in type II diabetes (UKPDS 56). Clin Sci (Lond) 2001; 101: 671-679.

4 Adler Al. UKPDS-modelling of cardiovascular risk assessment and lifetime simulation of outcomes. Diabet Med 2008; 25(Suppl 2): 41-46.

5 Mancia G, Parati G. Ambulatory blood pressure monitoring and organ damage. Hypertension 2000; 36: 894-900.

6 Parati G, Di Rienzo M, Mancia G. Neural cardiovascular regulation and 24-h blood pressure and heart rate variability. Ann NY Acad Sci 1996; 783: 47-63.

7 Shintani Y, Kikuya M, Hara A, Ohkubo T, Metoki H, Asayama K, Inoue R, Obara T, Aono Y, Hashimoto T, Hashimoto J, Totsune K, Hoshi H, Satoh H, Imai Y. Ambulatory blood 
pressure, blood pressure variability and the prevalence of carotid artery alteration: the Ohasama study. J Hypertens 2007; 25: 1704-1710.

8 Kikuya M, Hozawa A, Ohokubo T, Tsuji I, Michimata M, Matsubara M, Ota M, Nagai K, Araki T, Satoh H, Ito S, Hisamichi S, Imai Y. Prognostic significance of blood pressure and heart rate variabilities: the Ohasama study. Hypertension 2000; 36: 901-906.

9 Sander D, Kukla C, Klingelhofer J, Winbeck K, Conrad B. Relationship between circadian blood pressure patterns and progression of early carotid atherosclerosis: a 3-year follow-up study. Circulation 2000; 102: 1536-1541.

10 Eto M, Toba K, Akishita M, Kozaki K, Watanabe T, Kim S, Hashimoto M, Ako J, lijima K, Sudoh N, Yoshizumi M, Ouchi Y. Impact of blood pressure variability on cardiovascular events in elderly patients with hypertension. Hypertens Res 2005; 28: 1-7.

11 Shigenaga A, Tamura K, Dejima T, Ozawa M, Wakui H, Masuda S, Azuma K, TsurumiIkeya $Y$, Mitsuhashi H, Okano Y, Kokuho T, Sugano T, Ishigami T, Toya Y, Uchino K Tokita Y, Umemura S. Effects of angiotensin II type 1 receptor blocker on blood pressure variability and cardiovascular remodeling in hypertensive patients on chronic peritoneal dialysis. Nephron Clin Pract 2009; 112: c31-c40.

12 Mitsuhashi H, Tamura K, Yamauchi J, Ozawa M, Yanagi M, Dejima T, Wakui H, Masuda SI, Azuma K, Kanaoka T, Ohsawa M, Maeda A, Tsurumi-Ikeya Y, Okano Y, Ishigami T, Toya Y, Tokita Y, Ohnishi T, Umemura S. Effect of Iosartan on ambulatory short-term blood pressure variability and cardiovascular remodeling in hypertensive patients on hemodialysis. Atherosclerosis (e-pub ahead of print 11 April 2009).

13 Spallone V, Bernardi L, Ricordi L, Solda P, Maiello MR, Calciati A, Gambardella S, Fratino $\mathrm{P}$, Menzinger $\mathrm{G}$. Relationship between the circadian rhythms of blood pressure and sympathovagal balance in diabetic autonomic neuropathy. Diabetes 1993; 42: 1745-1752.

14 Monteagudo PT, Nobrega JC, Cezarini PR, Ferreira SR, Kohlmann Jr O, Ribeiro AB, Zanella MT. Altered blood pressure profile, autonomic neuropathy and nephropathy in insulin-dependent diabetic patients. Eur J Endocrinol 1996; 135: 683-688.

15 Ohkubo T, Imai Y, Tsuji I, Nagai K, Watanabe N, Minami N, Kato J, Kikuchi N, Nishiyama A, Aihara A, Sekino M, Satoh H, Hisamichi S. Relation between nocturnal decline in blood pressure and mortality. The Ohasama Study. Am J Hypertens 1997; 10: $1201-1207$

16 Nakano S, Fukuda M, Hotta F, Ito T, Ishii T, Kitazawa M, Nishizawa M, Kigoshi T, Uchida K. Reversed circadian blood pressure rhythm is associated with occurrences of both fatal and nonfatal vascular events in NIDDM subjects. Diabetes 1998: 47: 15011506.

17 Sturrock ND, George E, Pound N, Stevenson J, Peck GM, Sowter H. Non-dipping circadian blood pressure and renal impairment are associated with increased mortality in diabetes mellitus. Diabet Med 2000; 17: 360-364.

18 Kario K, Pickering TG, Matsuo T, Hoshide S, Schwartz JE, Shimada K. Stroke prognosis and abnormal nocturnal blood pressure falls in older hypertensives. Hypertension 2001: 38: 852-857.

19 Mancia G, Bombelli M, Facchetti R, Madotto F, Corrao G, Trevano FQ, Grassi G, Sega R. Long-term prognostic value of blood pressure variability in the general population: results of the Pressioni Arteriose Monitorate e Loro Associazioni Study. Hypertension 2007; 49: 1265-1270.

20 Palmas W, Pickering TG, Teresi J, Schwartz JE, Moran A, Weinstock RS, Shea S. Ambulatory blood pressure monitoring and all-cause mortality in elderly people with diabetes mellitus. Hypertension 2009; 53: 120-127.

21 Eguchi K, Ishikawa J, Hoshide S, Pickering TG, Schwartz JE, Shimada K, Kario K. Night time blood pressure variability is a strong predictor for cardiovascular events in patients with type 2 diabetes. Am J Hypertens 2009; 22: 46-51.

22 Galle J. Reduction of proteinuria with angiotensin receptor blockers. Nat Clin Pract Cardiovasc Med 2008; 5(Suppl 1): S36-S43.

23 Burnier M. Angiotensin II type 1 receptor blockers. Circulation 2001; 103: 904-912.

24 Bakris G, Burgess E, Weir M, Davidai G, Koval S. Telmisartan is more effective than losartan in reducing proteinuria in patients with diabetic nephropathy. Kidney Int 2008; 74: 364-369.
25 Imai E, Horio M, Nitta K, Yamagata K, Iseki K, Tsukamoto Y, Ito S, Makino H, Hishida A, Matsuo S. Modification of the Modification of Diet in Renal Disease (MDRD) Study equation for Japan. Am J Kidney Dis 2007; 50: 927-937.

26 Tamura K, Tsurumi Y, Sakai M, Tanaka Y, Okano Y, Yamauchi J, Ishigami T, Kihara M, Hirawa N, Toya Y, Yabana M, Tokita Y, Ohnishi T, Umemura S. A possible relationship of nocturnal blood pressure variability with coronary artery disease in diabetic nephropathy. Clin Exp Hypertens 2007; 29: 31-42.

27 Okano Y, Tochikubo O, Umemura S. Relationship between base blood pressure during sleep and health-related quality of life in healthy adults. J Hum Hypertens 2007; 21: $135-140$.

28 Yamashina A, Tomiyama H, Takeda K, Tsuda H, Arai T, Hirose K, Koji Y, Hori S, Yamamoto $Y$. Validity, reproducibility, and clinical significance of noninvasive brachialankle pulse wave velocity measurement. Hypertens Res 2002; 25: 359-364.

29 Remuzzi G, Benigni A, Remuzzi A. Mechanisms of progression and regression of renal lesions of chronic nephropathies and diabetes. J Clin Invest 2006; 116: 288-296.

30 Ragot S, Herpin D, Siche JP, Ingrand P, Mallion JM. Autonomic nervous system activity in dipper and non-dipper essential hypertensive patients. What about sex differences? J Hypertens 1999; 17: 1805-1811.

31 Tamura K, Yamauchi J, Tsurumi-Ikeya Y, Sakai M, Ozawa M, Shigenaga A, Azuma K, Okano Y, Ishigami T, Toya Y, Yabana M, Tokita Y, Ohnishi T, Umemura S. Ambulatory blood pressure and heart rate in hypertensives with renal failure: comparison between diabetic nephropathy and non-diabetic glomerulopathy. Clin Exp Hypertens 2008; 30: 33-43.

32 Tochikubo O, Ikeda A, Miyajima E, Ishii M. Effects of insufficient sleep on blood pressure monitored by a new multibiomedical recorder. Hypertension 1996; 27: 1318-1324.

33 Tokuhisa T, Yano M, Obayashi M, Noma T, Mochizuki M, Oda T, Okuda S, Doi M, Liu J, Ikeda Y, Yamamoto T, Ohkusa T, Matsuzaki M. AT1 receptor antagonist restores cardiac ryanodine receptor function, rendering isoproterenol-induced failing heart less susceptible to $\mathrm{Ca} 2+$-leak induced by oxidative stress. Circ J 2006; 70: 777-786.

34 Wong PC, Bernard R, Timmermans PB. Effect of blocking angiotensin II receptor subtype on rat sympathetic nerve function. Hypertension 1992; 19: 663-667.

35 Nap A, Balt JC, Pfaffendorf M, Van Zwieten PA. Sympatholytic properties of several AT1-receptor antagonists in the isolated rabbit thoracic aorta. J Hypertens 2002; 20: 1821-1828.

$36 \mathrm{Xi}$ GL, Cheng JW, Lu GC. Meta-analysis of randomized controlled trials comparing telmisartan with losartan in the treatment of patients with hypertension. Am J Hypertens 2008; 21: 546-552.

37 Mallion J, Siche J, Lacourciere Y. ABPM comparison of the antihypertensive profiles of the selective angiotensin II receptor antagonists telmisartan and losartan in patients with mild-to-moderate hypertension. J Hum Hypertens 1999; 13: 657-664.

38 Smith DH, Cramer MJ, Neutel JM, Hettiarachchi R, Koval S. Comparison of telmisartan versus losartan: meta-analysis of titration-to-response studies. Blood Press Monit 2003; 8: 111-117.

39 Nishimura T, Hashimoto J, Ohkubo T, Kikuya M, Metoki H, Asayama K, Totsune K, Imai Y. Efficacy and duration of action of the four selective angiotensin II subtype 1 receptor blockers, losartan, candesartan, valsartan and telmisartan, in patients with essential hypertension determined by home blood pressure measurements. Clin Exp Hypertens 2005; 27: 477-489.

40 Ishikawa T, Hashimoto J, Morito RH, Hanazawa T, Aikawa T, Hara A, Shintani Y, Metoki H, Inoue R, Asayama K, Kikuya M, Ohkubo T, Totsune K, Hoshi H, Satoh H, Imai Y. Association of microalbuminuria with brachial-ankle pulse wave velocity: the Ohasama study. Am J Hypertens 2008; 21: 413-418.

41 Ohya Y, Iseki K, Iseki C, Miyagi T, Kinjo K, Takishita S. Increased pulse wave velocity is associated with low creatinine clearance and proteinuria in a screened cohort. $\mathrm{Am} \mathrm{J}$ Kidney Dis 2006; 47: 790-797. 